\title{
Promoção da saúde e redes de lideranças
}

I 1 Rosilda Mendes, 2 Cláudia Maria Bógus,

${ }^{3}$ Marcia Faria Westphal, 4 Juan Carlos Aneiros Fernandez I

Resumo: O estudo das redes sociais vem ganhando importância no campo da promoção da saúde, dadas a horizontalidade e a sinergia que suscitam ao agregarem grupos em torno de iniciativas que melhoram as condiçōes de vida. Este trabalho apresenta parte dos resultados da investigação "Capela em Ação e a gestão integrada e participativa de políticas públicas", que teve como objetivo avaliar um modelo de gestão da subprefeitura de Capela do Socorro, localizada ao sul da cidade de São Paulo. A análise dos dados foi dedicada ao estudo das relaçôes existentes entre as lideranças locais e sua articulação em redes e ao quanto elas facilitam ações voltadas para a melhoria das condiçōes de vida. $\mathrm{O}$ universo de líderes e entidades não foi definido a priori, mas a partir da técnica da bola de neve (snowball). As informaçôes foram obtidas por meio de entrevista semiestruturada, o que permitiu a identificação de grupos, movimentos e entidades e das relaçôes que estabelecem entre si e com o poder público. Os dados mostraram 247 lideranças e 342 associações, bem como a complexidade do modelo de gestão do ponto de vista da construção de redes sociopolíticas como instrumentos de fortalecimento da participação. Nesta pesquisa, pôde-se verificar que mudanças vêm acontecendo na sociedade civil, tanto em termos da sua organização, quanto no desempenho de um papel transformador da realidade. Alguns elementos apontados neste artigo podem subsidiar a gestão local no sentido da criação de espaços de participação que facilitem o engajamento nas políticas públicas.

> Palabras-clave: promoção da saúde; redes sociais; intersetorialidade; participação social.

\author{
1 Professora da Universidade \\ Federal de São Paulo, Campus \\ da Baixada Santista e CEPEDOC \\ Cidades Saudáveis. Endereço \\ eletrônico: rosildamendes@ \\ terra.com.br \\ 2 Professora do Departamento \\ de Prática de Saúde Pública da \\ Faculdade de Saúde Pública \\ da USP e CEPEDOC Cidades \\ Saudáveis. Endereço eletrônico: \\ claudiab@usp.br \\ ${ }^{3}$ Professora do Departamento \\ de Prática de Saúde Pública da \\ Faculdade de Saúde Pública \\ da USP e CEPEDOC Cidades \\ Saudáveis. Endereço eletrônico: \\ marciafw@usp.br \\ ${ }^{4}$ Professor do Departamento \\ de Saúde Coletiva da Faculdade \\ de Ciências Médicas da \\ Universidade Estadual de \\ Campinas e CEPEDOC Cidades \\ Saudáveis. Endereço eletrônico: \\ juanfernandez@usp.br
}




\section{Redes sociais para promover saúde}

Nas últimas décadas, foram identificadas em todo o mundo, nos campos da Economia, Política e Cultura, inúmeras redes e organizaçôes na esfera da sociedade civil lutando pela promoção das liberdades públicas e privadas eticamente exercidas, novas formas de associativismo que emergem na cena política. Isso decorre de um descentramento do sujeito, foco dos discursos e práticas dos movimentos sociais nos anos 80 , para a emergência de uma pluralidade de atores e da ideia de participação como exercício de civilidade que trata de direitos e também de deveres na construção de políticas públicas sociais (GOHN, 2005). São redes e organizações feministas, ecológicas, movimentos nas áreas de educação, saúde, moradia, espaços como o Fórum Social Mundial e muitos outros. Todos esses propõem para o mercado e para o Estado transformações nas relaçôes desiguais existentes da sociedade.

Verifica-se, neste século, um ganho de relevância da noção de redes, não só nas ciências humanas e sociais, mas em diversos campos do conhecimento, inclusive nas ciências naturais e exatas. Destaca-se neste artigo o entendimento das redes como interações complexas entre pessoas ou entidades que se unem com determinado objetivo, tendo como ideário uma nova visão do processo de mudança social-a qual considera fundamental a participação cidadã (SCHERER-WARREN, 1999). Scherer-Warren (2007) reitera o papel das redes interorganizacionais no combate da exclusão, uma vez que a partir do seu reconhecimento é possível planejar e implementar projetos de desenvolvimento social, associando as dimensões de condições materiais de existência (desigualdade, pobreza) com as dimensões simbólicas de sua reprodução (estigma, discriminação), e ainda com as condiçôes políticas decorrentes (subcidadania, desempoderamento). Chama-se a atenção, entretanto, para a necessidade de que os participantes das redes tenham um reconhecimento recíproco sobre a vivência da exclusão ou da discriminação, e resolvam unir-se para a tradução dessa vivência em novos valores coletivos dos grupos e para a construção em redes de pautas políticas emancipatórias.

As redes representam também uma possibilidade para o estabelecimento de relações mais horizontais entre atores e, portanto, uma alternativa às tradicionais e predominantes relações hierarquicamente estruturadas de modo vertical ou piramidal. Assim, certa racionalidade instrumental que preside esse entendimento no tocante aos resultados que as redes podem oferecer se aplicaria também aos 
processos que elas seriam capazes de deflagrar. Ou seja, o exercício da liberdade e de democratização da informação, que a lógica horizontal de redes poderia desenvolver, ajudaria a reflexão dos participantes sobre os padrões de dominação, competição, autoritarismo e manipulação que a cultura do mundo atual introjeta em todas as pessoas (WHITAKER, 2002).

Para esse entendimento, então, e com certa dose de idealização, a rede seria uma forma de exercício de poder conjunto de todos que a integram, sendo que a maior disposição para compartilhar informações e identificar e estabelecer objetivos comuns e/ou complementares é o que ampliaria a possibilidade dela se efetivar como espaço de encontro e intercâmbio para promover ações de caráter coletivo.

Outro tema recorrente e de igual importância a ser considerado nos modelos reticulares é o de "estruturas de comunicação", desenvolvidas e consolidadas pelo uso de novas tecnologias criadas com o progresso técnico, as quais facilitam a livre circulação de informações. Segundo Castells (1999), as novas tecnologias da informação estão integrando o mundo em redes globais de instrumentalidade. A comunicação intensificada pelo uso de computadores interligados gera uma gama enorme de comunidades virtuais. As atuais possibilidades oferecidas pela informática - a rapidez da comunicação e a estocagem da informação - podem dar uma extrema eficácia a redes constituídas com objetivos específicos, bem como lhes assegurar efetivamente plena liberdade de circulação de informações. Redes de entidades ou de pessoas podem ter como apoio a rede de comunicação virtual. O que se observa nos dias de hoje é uma expansão em todos os segmentos da sociedade do uso de redes sociais informatizadas. Coloca-se, assim, em questão a necessidade de enfrentar os novos fenômenos munidos de instrumentos que permitam compreender a dinâmica sociocultural atual e os novos espaços ocupados pelos atores políticos (CASTELLS, 1999; CASTELLS, 2006).

Outras perspectivas e enfoques de redes apontam as potencialidades de seu emprego na advocacia e na formulação de políticas públicas urbanas que envolvam relações entre Estado e sociedade (MARQUES, 1999; GURZA LAVALLE et al., 2004, 2007, 2008). Gurza Lavalle e seus colaboradores (2004; 2007, 2008), em estudos sobre protagonismos e redes no seio da sociedade civil, realizados no município de São Paulo, analisaram as centralidades de organizações civis nos dias de hoje e concluíram que os movimentos sociais mantiveram seu 
protagonismo no cenário da ação coletiva também no contexto das redes, mas agora compartilhado com novos atores da sociedade civil.

Stotz (2009), ao realizar uma revisão bibliográfica sobre as redes sociais para averiguar a apropriação do conceito na saúde pública, indicou poucos estudos do tema relacionados à saúde. Em geral, a revisão apontou que as redes sociais estão relacionadas mais frequentemente ao apoio social, à solidariedade, à focalização e gestão de políticas sociais e ao compromisso social. Ao associar a definição de redes sociais ao conceito de "junção", o autor destaca nos estudos a "imbricação de redes primárias e redes secundárias”. Em sua proposição, as redes sociais primárias, organizadas em territórios locais, municipais ou nacionais, correspondem

às relações significativas que uma ou mais pessoas estabelecem cotidianamente ao longo de suas vidas (relações de familiaridade, parentesco, vizinhança, amizade etc.) e que respondem ao processo de socialização dos indivíduos. O processo é autônomo, espontâneo e informal. Já as redes sociais secundárias formam-se pela atuação coletiva de grupos, instituições e movimentos que defendem interesses comuns (STOTZ, 2009, p. 29).

As redes sociais vêm ganhando espaço e importância também no campo da promoção da saúde, em razão da forte expectativa quanto a sua capacidade de agregar grupos e indivíduos em torno de iniciativas que possibilitem melhorar as condições de vida e saúde. Tal capacidade decorreria da possibilidade das redes potencializarem processos participativos e integrados e estreitarem vínculos para apoiar grupos ou pessoas no enfrentamento de problemas e situações diversas.

Essas constatações nos levam a pensar a promoção da saúde de forma mais ampla, a partir da atuação que privilegia dois enfoques: o da autonomia e o da ação sobre os determinantes sociais. O primeiro deles compreende que a promoção da saúde vai além de uma explicação técnica e normativa. A autonomia "diz respeito ao fortalecimento da saúde por meio da construção da capacidade de escolha, bem como à utilização do conhecimento com o discernimento de atentar para as diferenças e singularidades dos acontecimentos" (CZERESNIA, 2003, p. 48). Promover a saúde "envolve escolha, e isso não é da esfera do conhecimento verdadeiro, mas do valor" (p.49). Esses argumentos podem ser compreendidos como uma ampliação, pois tratam da singularidade e da autonomia dos sujeitos, abrindo espaço para que a promoção da saúde se inscreva nos campos da Ética e da Política. 
A promoção da saúde funda-se na ideia de ampliação do controle dos indivíduos

sobre suas vidas e sua saúde, mediante a participação ativa e os processos de empoderamento de indivíduos e comunidades. Tal controle requer ações autônomas quando o que se visa é à transformação de uma dada realidade, e não apenas à substituição de um constrangimento por outro. É nesse sentido que a autonomia diz respeito às "atitudes ou comportamentos de usuários de serviços ou programas de promoção da saúde, mas também [às] práticas dos agentes, profissionais e gestores que os oferecem e desenvolvem" (FERNANDEZ, 2012, p. 500).

O segundo dos enfoques de atuação é o da promoção da saúde com base numa perspectiva ampliada que privilegia a ação sobre os determinantes sociais da saúde. O termo se refere ao papel protagonista dos determinantes sociais, econômicos, políticos, educacionais, ambientais e culturais sobre as condições de saúde (OMS, 2012). Depreende-se daí que a produção da saúde é social e resultante da ação de muitos setores, atores e saberes diversos. Nesse sentido, podem também ser destacados como componentes fundamentais da promoção da saúde os laços de coesão social e as relações de solidariedade e confiança entre pessoas e grupos. Neles, são incluidas políticas que buscam estabelecer redes de apoio local e fortalecer a organização e participação das pessoas e das comunidades, especialmente dos grupos vulneráveis, em ações coletivas para a melhoria de suas condições de vida e saúde (BUSS; PELLEGRINI, 2007; OMS, 2012).

O conjunto de potencialidades e expectativas sobre as redes sociais, destacado pelas perspectivas sumarizadas, guarda estreita relação com o ideário da promoção da saúde nessa ampla perspectiva. A busca da autonomia, da partilha do poder, do protagonismo social e político e de uma solidariedade socialmente orientada são promessas relativas às redes e compromissos assumidos pela promoção da saúde.

$\mathrm{O}$ processo recente em que emergem e se desenvolvem as redes sociais corresponderia ao que é para a promoção da saúde a dinâmica de territórios como espaços permanentes de construção, desconstrução e reconstrução de processos relacionais, a qual revela a pluralidade, as diferenças, as singularidades, a heterogeneidade e, sobretudo, a potência de atores.

O reconhecimento da tessitura de territórios permite conhecer as condições em que os indivíduos moram, vivem, trabalham, adoecem, amam e se relacionam. Territórios são espaços da política, permeados, portanto, por disputas, conflitos, 
relações de poder e iniquidades, mas são também dotados de simbologia, de distintas identidades, representaçōes, imaginários e subjetividades. Essa dupla significação traz inúmeros desafios e parece ser um profícuo horizonte à produção social da saúde, tanto na inclusão de diversos sujeitos locais no estabelecimento de políticas públicas de melhoria das condições de vida e saúde, como na tomada de decisões partilhadas. Isso torna o processo mais legítimo, produto do debate e da reflexão conjunta e ainda favorecedor do aprendizado mútuo.

\section{Modelo de gestão, caracterização e identificação de lideranças locais}

Este artigo aborda a configuração das redes sociais identificadas na investigação "Capela em Ação e a gestão integrada e participativa de políticas públicas" (2005-2008), planejada para acompanhar um modelo de gestão proposto em uma subprefeitura da cidade de São Paulo. ${ }^{1}$ Denominado "Capela em Ação", o modelo foi criado baseando-se no entendimento de que uma atuação organizada sobre as demandas das comunidades, em perspectiva intersetorial e participativa, ampliaria a confiança em relação à gestão local.

Duas áreas da região foram estudadas de distintas maneiras nos dois anos de desenvolvimento do projeto, em momentos diferentes do processo de implantação do modelo de gestão. A pesquisa, em cada área, foi iniciada com uma abordagem diagnóstica do território, por meio de dados demográficos, socioeconômicos e ambientais, georreferenciados para a identificação de "ilhas de exclusão". O estudo do território foi complementado por dados relativos às percepções da população sobre a realidade. A análise do tecido social, das redes sociais existentes, ocorreu concomitantemente ao acompanhamento do processo de gestão dos problemas dos territórios.

O que se destaca neste artigo é o estudo da configuração dessas redes de entidades existentes e em ação em parte do território, bem como de suas relações. $\mathrm{O}$ pressuposto do estudo foi o de que pessoas que vivem em um determinado território desenvolvem no seu cotidiano padrões de sociabilidade em função das relações que estabelecem e das atividades que realizam.

Ao analisar a dinâmica social que permeava as redes de relações existentes entre pessoas e entidades que se relacionavam no território, isto é, a teia de relações que agregavam, fragmentavam ou segmentavam os atores, sujeitos 
sociais que habitavam o território da Capela do Socorro, buscou-se compreender a iniciativa do ponto de vista da construção de alianças e de redes sociopolíticas como instrumentos de fortalecimento da participação social e entender como estas se organizavam e se conformavam em redes de relações. Essa parte do estudo objetivou, portanto, avaliar se o modelo de gestão posto em prática incorporava um dos pressupostos do ideário de cidades saudáveis: ${ }^{2}$ a participação da população no tipo de gestão em implementação.

A primeira etapa do estudo do tecido social foi o mapeamento de lideranças - identificação e mapeamento de grupos, movimentos, organizações e entidades que atuam na área do estudo - e das relações que elas estabeleciam entre si e com o poder público.

O universo dos atores foi definido empiricamente pela técnica snowball, bastante utilizada em análises de redes sociais, e pela saturação de informaçôes. Foram realizadas entrevistas individuais com informantes-chave, designados por pessoas da comunidade, em razão da qualidade de liderança e das relações e fluxos de informações que estabeleciam intra e interterritorialmente entre si, com a população em geral, e com o poder local. A cadeia de referência de atoreschave foi obtida passo a passo, a partir de três indicações de atores, líderes locais, considerados pontos de entrada das redes. Cada ator identificado poderia citar até três outros de sua relação, em ordem de importância, e assim por diante, colaborando cada um a sua vez para a reconstrução da malha social local (BIERNACKI; WALDFORD, 1981; LOPES et al.,1996).

O instrumento de coleta de dados utilizado para a realização desse levantamento buscava, em um primeiro conjunto de questôes, caracterizar o entrevistado do ponto de vista socioeconômico e da atividade principal que desenvolvia, além de conhecer suas fontes de informação. O segundo bloco de questôes buscava identificar sua experiência, sua participação em entidades ou associações, as características principais destas e suas relações com outras instituiçôes. No terceiro, buscava-se identificar as relações da liderança entrevistada com as demais da região. No quarto bloco, a liderança era solicitada a indicar até três outras que julgava importantes para participarem de reuniōes e ou discussões com a subprefeitura. O quinto bloco continha perguntas sobre a participação da liderança no Projeto Capela em Ação e sobre sua avaliação do processo e dos resultados que ela produzia. No último bloco, a liderança indicava outras lideranças para serem entrevistadas. 
Para a etapa seguinte, de análise do tecido social, ou seja, da relação entre as lideranças e suas instituições, foi utilizado o programa Ucinet 6.0 (BORGATTI et al., 2002), que permitiu, entre outras coisas, a identificação e a representação gráfica das redes existentes, seus nós e fluxos, e o cálculo da intensidade das relações no interior delas. (BORGATTI et al., 2002)

Para a elaboração e representação gráfica das redes, conforme o programa, foi necessária a criação de uma matriz de relações que indicasse os vínculos e fluxos dos nós e auxiliasse no cálculo dos indicadores. Os dados obtidos nas entrevistas foram então alocados nas linhas e colunas, respectivamente a representação dos atores entrevistados e suas relações com os outros atores. Foi construída a matriz inserindo-se para cada ator os números zero - no caso de não existir relação - ou um - quando havia relação -, conforme pré-requisito do software.

A matriz construída representou, então, uma medida-resumo dos dados obtidos, necessária para elaboração dos cálculos que permitiriam identificar e caracterizar cada ator e o seu papel na rede social em análise, e ainda para a elaboração e representação gráfica dos vínculos e fluxos dos nós da rede.

A partir dessa perspectiva, buscou-se identificar junto às lideranças locais o grau de centralidade que se apresentava no relacionamento entre eles, ou seja, se era possível reconhecer grupos ou claques em que cada ator está direta e fortemente ligado a todos os outros (MARTELETO et al., 2002).

Três conceitos, de acordo com Borgatti e seus colaboradores (2002), são fundamentais para a análise da centralidade em uma rede social:

1. A centralidade de grau (degree): quantidade de relacionamentos que um ator mantém, o que determina mais oportunidades e alternativas em relação a outros atores;

2. A centralidade de proximidade (closeness): quantidade de ligaçōes necessárias para se relacionar com um ator a partir da distância geodésica de um para o outro. $\mathrm{O}$ conceito de proximidade tende a corrigir distorçôes em relação à mensuração da centralidade baseada apenas no grau, principalmente quando se considera a comunicação, no sentido de que as ligações diretas com determinado ator não indicam a conectividade dos sujeitos em relação a outros distribuídos na rede;

3. A centralidade de intermediação (betweenness): a posição favorável de um ator em relação à rede, de forma a estabelecer caminhos entre dois pares de sujeitos na rede. 
Diz-se que um ator é proeminente ou tem alto prestígio pela quantidade de indicações que recebe, no exame do grau de centralidade, quando se analisam dados diretos, a distinção entre in-degree e out-degree, termos relacionados ao sentido da indicação, ou seja, à quantidade de ligaçôes diretas recebidas por outros atores ou, ao contrário, deste em direção aos outros. Um alto grau de out-degree indica que o ator tem grande capacidade de influenciar outros atores.

\section{Lideranças locais: como se relacionam entre si e com a política local}

Os resultados permitiram identificar 247 lideranças locais que nomearam 342 associações das quais faziam parte. Havia uma distribuição equilibrada das lideranças em relação ao sexo, sendo que os homens representavam 52,2\% da amostra. Havia uma concentração de lideranças com idades que variavam dos 40 aos 59 anos (56,2\% dos casos). Na faixa etária dos 30 aos 39 anos estavam cerca de $20 \%$ dos casos. Pouco mais de $13 \%$ correspondiam a lideranças com até 29 anos, e apenas 10,9\% a lideranças com 60 anos ou mais. A média de idade encontrada foi de 45 anos e a mediana, 46.

Mais da metade das lideranças identificadas residia havia 20 anos ou mais no mesmo bairro, e quase um terço entre 10 e 20 anos. Somados esses dois casos, o percentual chegava a $84,6 \%$ das lideranças, enquanto $6,8 \%$ dos atores residiam havia menos de 5 anos. Esse dado é bastante relevante, pois indica que as lideranças eram moradores antigos da região e, assim, conviviam havia mais tempo com os problemas, demandas e necessidades de transformações nos territórios locais.

A maioria das associações tinha entre 11 e 30 membros (37,8\%), sendo o segundo maior grupo o composto por associações com mais de 100 membros (21,5\%). Eram similares as entidades com até 10 membros $(19,3 \%)$ e as que continham entre 31 e 100 membros (18,5\%).

A maioria dos entrevistados participava de algum movimento ou associação, representando $94,3 \%$ do total de 247 lideranças. Os dados mostraram também que mais da metade dos entrevistados, 146 (59\%), participava apenas de uma organização. Contudo, é importante destacar o elevado número de lideranças que participavam de duas associações (65 casos ou $26,3 \%$ ). Aqueles que participavam de três associações correspondiam a 8,9\%. 
As atividades desenvolvidas pelas associações foram elencadas de forma espontânea pelos respondentes e, posteriormente, agrupadas por tipo. Observa-se que elas eram muito diversificadas e se concentravam em atividades de formação, como cursos, palestras, eventos, e em atividades assistenciais, como distribuição de leite, alimentos e cestas básicas.

Menos referidas foram as atividades voltadas à organização da comunidade para reivindicaçōes junto ao poder público. Apesar disso, no agrupamento dos principais objetivos perseguidos pelas associações, predominaram os relacionados à melhoria do bairro, e, em menor número, os que buscavam desenvolver trabalhos com a comunidade ou organizar os moradores em torno de reivindicaçōes e problemas específicos. Destacaram-se também os objetivos voltados à garantia de serviços específicos, como moradia, creches, meio ambiente, lixo, segurança, cultura, frequentemente referidos pelos entrevistados. Considerados em conjunto, representaram a maioria das respostas das lideranças.

Foi muito significativa também a ocorrência de objetivos voltados para a atenção a grupos sociais específicos, especialmente meninas, crianças e adolescentes/jovens, bem como o número expressivo de objetivos relacionados à atenção às pessoas necessitadas, excluidas e aos imigrantes. Outros objetivos, por fim, referiram-se à ação social, serviço social e inclusão social.

As entidades relacionavam-se umas com as outras para realizarem açōes específicas, como campanhas de vacinação, comemorações no bairro, cursos e outros. Esses tipos de ações receberam o maior número de menções entre os entrevistados, 174 respostas. As associações se relacionam também, segundo os entrevistados, para obter benefícios para os bairros, citados 79 vezes. O principal objetivo de relacionamento entre as entidades, segundo 73 respondentes, é a troca de informaçôes. As parcerias foram indicadas por 71 sujeitos. Nessa categoria, foram também adicionadas as menções ao trabalho conjunto e à ideia de "unir forças". Também é relevante o número de respostas que sugeriu que as associaçóes se relacionam umas com as outras para troca de ideias e de experiências (39). Poucas entidades, no entanto, se relacionavam para acompanhar e planejar as políticas locais.

Dentre aqueles que nunca participaram do Projeto Capela em Ação, 132 pessoas, 35 afirmaram que nunca foram convidadas a participar das atividades. 
A pesquisa revelou que a falta de conhecimento sobre o projeto foi o motivo mais citado (39 pessoas), sendo que alguns dos que desconheciam o projeto disseram que "não sabiam como participar". Isso contribuiu para a apreensão dos resultados do projeto mais abrangente do qual o estudo dessas redes é parte, pois evidenciou que o modelo de gestão local que estava em implantação - e sua natureza supostamente participativa - não logrou envolver, de fato, as lideranças e as organizações no processo de gestão. Da mesma forma, evidenciou-se que o conjunto de atores não identificava nas instâncias criadas por esse modelo uma efetiva possibilidade de intervenção.

Os dados processados pelo programa Ucinet geram figuras de alta complexidade que podem ser trabalhadas no ambiente do sistema. Para efeito ilustrativo, apresentamos uma dessas figuras (Figura 1), que retrata a distribuição e relacionamento de lideranças no levantamento realizado.

\section{Figura 1 - Sociograma da rede social das lideranças do Projeto Capela em Ação}

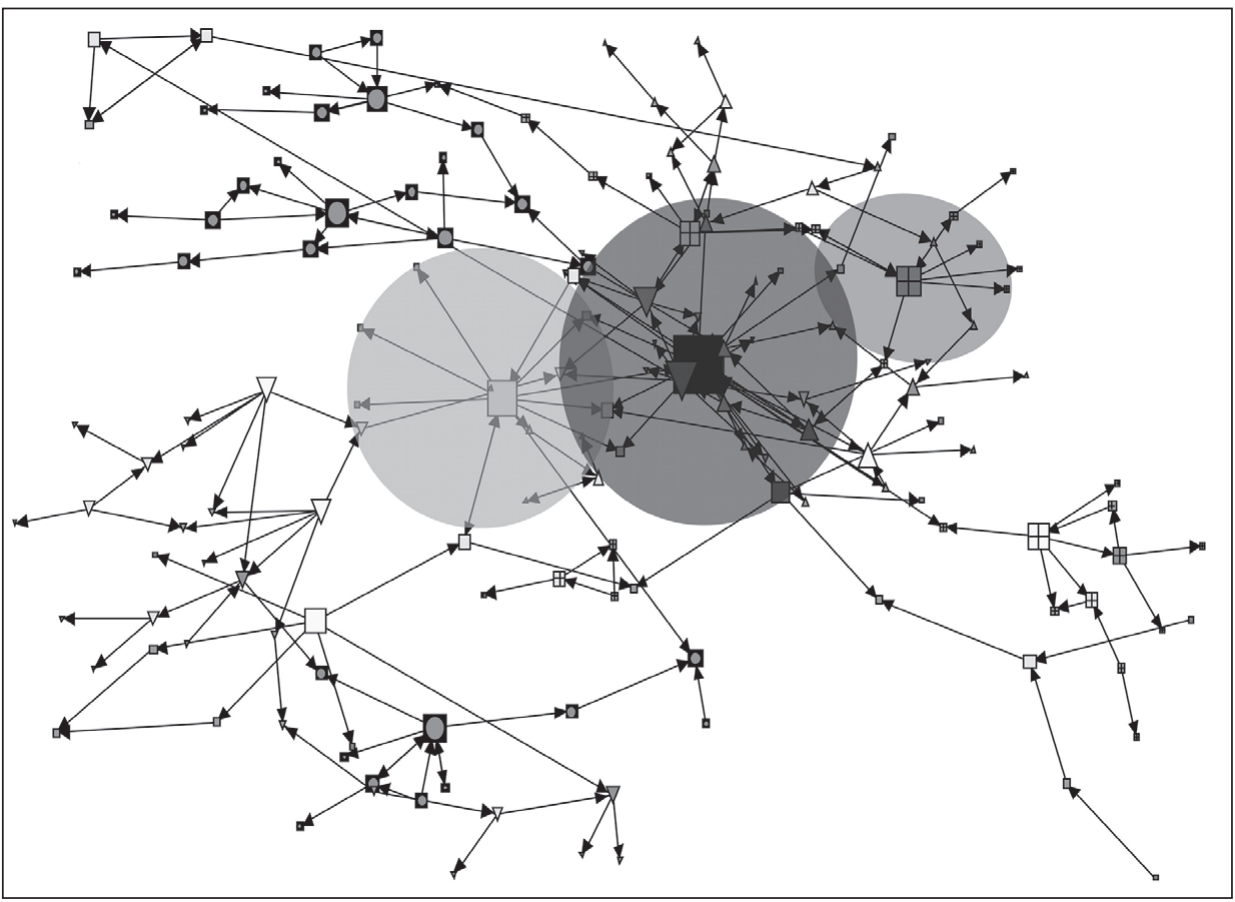

Fonte: Westphal et al. (2008). 
Os dados indicaram que o grau de centralidade da rede de lideranças identificadas é baixo tanto no out-degree, como no in-degree, resultado de uma rede bastante extensa. A dimensão de relações possíveis a partir da matriz construída foi de 60.762 ligaçôes, ou seja, o produto de 247 x (247-1).

Do conjunto de 247 atores, apenas três detinham os maiores graus de centralidade, como pode ser observado no destaque da figura, com os maiores escores absolutos de números de ligações, respectivamente, 14, 9 e 9 ligações. Esses atores eram líderes de associaçóes de bairros com pelo menos 15 anos de residência na região. O grau de out-degree dessas lideranças indicava que possuíam alto grau de prestígio e que exerciam grande influência sobre a rede.

A centralidade de intermediação consiste na possibilidade de alcançar um ator com o qual não se tem ligação direta, ou seja, vê a posição de um ator na ligação com outros pares de atores na rede. O sociograma indicou alguns atores que desfrutavam dessa posição favorável e serviam como ligação entre as lideranças e grupos.

A formação de grupos ou claques permite entender a estrutura social e o encaixe dos atores na rede social. A claque é um subconjunto de atores mais fortemente ligados entre si do que com outros fora do grupo. Foi possível localizar vários grupos (tendo em vista a quantidade de atores e a proximidade entre eles), representados por figuras geométricas de tamanhos diferentes que variam em função do grau de centralidade dos atores.

\section{Reflexões sobre a experiência}

Os dados evidenciam que a região apresentava um grande número de lideranças que se conectavam entre si de diversas maneiras e com diferentes objetivos. $\mathrm{O}$ mapeamento realizado pela pesquisa permitiu algumas descobertas importantes. No início do processo de identificação e mapeamento das lideranças, não se imaginava a possibilidade de encontrar uma rede tão extensa e única, com pelo menos cinco lideranças concentrando a centralidade dos relacionamentos.

Os resultados obtidos confirmam os estudos de Gurza Lavalle e seus colaboradores (2007), segundo os quais é uma premissa, do ponto de vista teórico, que em redes muito grandes seja comum uma baixa densidade de relaçôes; isto é, quanto maior a rede, maior a dificuldade de cada ator ocupar posição com alto grau de centralidade. De forma geral, o relacionamento entre os 
grupos que compunham a rede estudada demonstra que havia uma conectividade difusa notável entre esses grupos, caracterizada por uma rede extensa e de relacionamentos esparsos e, portanto, bastante esgarçada. Além disso, a rede ocupava todo território e por vezes ultrapassava seus limites geográficos.

Esse resultado problematiza a ideia das redes como exercício de poder conjunto e a possibilidade de promoção de ações de caráter coletivo, como apresentado no início. $\mathrm{Na}$ ausência de um foco comum de interesse ou de um objetivo único definido por seus integrantes, também não se pode concluir que a rede apresente uma horizontalidade de relações, pois há entre as entidades que a compõem uma profusão de objetivos, e não uma pulverização identificável de relações de poder de base hierárquica nos processos, seja para definir esses objetivos, seja para atingi-los. Por outro lado, também a ausência de um projeto comum para a rede não permite associar a presença destacada de pontos de centralidade a uma ação hierárquica desses sobre os demais pontos.

As redes não parecem, portanto, formadas por uma lógica instrumental e voltadas para um fim determinado. Elas chamam a atenção mais para uma dimensão substantiva, isto é, o que elas expressam como tal é certo modo do fazer social e político atual.

Considerando-se a conformação da rede representada na figura 1, percebe-se a existência de potencialidade de uma conectividade difusa entre um número considerável de grupos que a compunham. Essa rede e seus atores, quando identificados por endereço, indicavam a existência de vínculo territorial, ou seja, estavam distribuídos em torno de áreas identificáveis e circunscritas. É possível considerar que essa característica resulta do processo histórico de ocupação de áreas de preservação na região sul da cidade de São Paulo. Muitos desses bairros ou vilas são relativamente novos e não completaram ainda 20 anos de existência. As inúmeras carências da região têm exigido dos líderes uma atuação centrada em demandas ao poder público por melhorias nos bairros de moradia, o que os leva a competir entre si pelo atendimento das mesmas necessidades.

Scherer Warren (2008), ao comentar sobre a possibilidade de construção de sujeitos por meio da atuação em redes e a dificuldade de transformação destes em atores politicamente ativos, faz-nos lembrar que a carência por si só não produz movimentos sociais e políticos. Segundo a autora,

o movimento resulta do sentido coletivo atribuído a essa carência e da possibilidade de identificação subjetiva em torno dela. Resulta também da subsequente transfor- 

demandas, dessas demandas em pautas políticas e das pautas políticas em ações de protesto. (SCHERER WARREN, 2008, p.508)

Os dados analisados indicam que as entidades e lideranças que constituem essa rede atuam de forma fragmentada, sem se articularem entre si para resolver os problemas da região. Segundo Boaventura Santos, citado por Scherer Warren (2008, p.508), para que essa articulação seja possível, seria necessário "um trabalho de tradução", que poderia ter sido realizado como uma tarefa no "Projeto Capela em Ação". As definiçôes das açôes do projeto obedeceram, no entanto, à lógica da disponibilidade dos recursos e dos cronogramas previamente definidos, sugerindo, assim, que o processo participativo teve muito mais a função de mobilizar pessoas ou grupos em torno da gestão para se obter deles um consentimento informado.

Reconhecendo essa rede, com os atributos que este estudo identificou, a gestão pública local poderia se recolocar de modo mais permeável e também mais eficaz na relação com seus territórios. $\mathrm{O}$ desenho dessa rede indica pontos importantes, a partir dos quais se podem emitir mensagens que se pretende disseminar e receber outras que supostamente têm maior capilaridade no território. Da mesma forma, esse desenho permite identificar a necessidade de investimentos diferenciados para atingir pontos da rede que apresentam menor comunicação e articulação, promovendo dessa forma, também, mais equidade.

Há que se ressaltar que o Projeto Capela em Ação, como um modelo de gestão integrada e participativa, analisado a partir do referencial de Cidades Saudáveis, tem valor se considerado um ponto de partida de um processo em constante transformação. O papel dessa investigação foi o de dar subsídios para reflexôes e possíveis aprimoramentos. Nesse sentido, a inclusão da sociedade civil e a aproximação do poder público às redes sociais que se organizam no território parecem ser um profícuo horizonte para o desenvolvimento da gestão local.

Os resultados aqui apresentados poderão ser aprofundados como objeto de novas análises a partir de enfoques específicos do estudo sobre as redes sociais. O desafio é ir além da identificação dos grupos e atores que integram a rede e a densidade de seus relacionamentos. É preciso verificar a profundidade do envolvimento dos cidadãos em tais grupos, assim como a qualidade do relacionamento estabelecido entre os cidadãos e grupos sociais e governos. É 
necessário, além disso, procurar entender como a sociedade civil pode efetivamente influenciar processos políticos de tomada de decisão.

$\mathrm{Na}$ pesquisa, por meio das várias abordagens utilizadas nesta investigação, não foi possível ainda encontrar resposta para essa questão. Contudo, alguns elementos podem ser oferecidos como subsídios para a gestão local sobre a estrutura e a organização das lideranças, para que a abertura de espaços de participação facilite o seu engajamento nas questões públicas. Esse parece ser um fecundo terreno para se recolocar a questão da gestão de políticas públicas, dado o potencial de questionamento que a noção de rede traz consigo em relação às estruturas hierarquizadas, sejam elas de pensamento, conhecimento, poder, comunicação ou de processos sociais e coletivos ${ }^{3}{ }^{4}$.

\section{Referências}

BIERNACKY, P.; WALFORD, D. Snowball sampling: problems and techniques of chaim referral sampling. Sociol Methods Research, n. 2, p. 141-163, 1981.

BORGATTI, S.P.; EVERETT, M.G.; FREEMAN, L.C. Ucinet for Windows: Software for Social Network Analysis. Harvard: Analytic Technologies, 2002.

BUSS, P.M.; PELLEGRINI FILHO, A. A saúde e seus determinantes. PHYSIS: Rev. Saúde Coletiva, Rio de Janeiro, v.17, n.1, p.77-93, 2007

CASTELLS, M. A sociedade em rede. São Paulo: Paz e Terra, 1999.

O poder da identidade. In: . A era da Informação, Sociedade e Cultura. V.2. São Paulo: Paz e Terra, 2006.

CZERESNIA, D. O conceito de saúde e a diferença entre prevenção e promoção. In: CZERESNiA, D.; FREITAS, C.M. (Org.) Promoção da Saúde: conceitos, reflexôes, tendências. Rio de Janeiro: Fiocruz, 2003.p. 39-53.

FERNANDEZ, J.C.A. Autonomia e promoção da saúde. In: PELICIONI M.C.F.; MIALHE, F.L. (Ed.). Educação e promoção da saúde: teoria e prática. São Paulo: Santos, 2012, p. 499-512.

GOHN, M.G. Protagonismo da sociedade civil: movimentos sociais, ONG's e redes solidárias. São Paulo: Cortez, 2005 (Coleção Questões da Nossa Época, v.123).

GURZA-LAVAlLE, A.G.; CASTELLO, G.; BICHIR, R.M. Quando novos atores saem de cena - continuidades e mudanças na centralidade dos movimentos sociais. Política \& Sociedade. Florianópolis, v.5, n.2, p.35-54, 2004.

Protagonistas na sociedade civil: redes e centralidades de organizações civis em São Paulo. Dados. Rio de Janeiro, v.50, n.3, p.465-498, 2007. 

. Atores periféricos na sociedade civil: redes, centralidades e organizações civis em São Paulo. Revista Brasileira de Ciências Sociais, v.23, n.68, p.73-96, 2008.

LOPES, C.S.; RODRIGUES, L.C; SICHIERI, R. The lack of selection bias in a snowball sampled case-control study on drug abuse. International Journal of Epidemiology, v. 25, n.6, p.1267-1270, 1996.

MARQUES, E.C. Redes sociais e institucionais na construção do Estado e da sua permeabilidade. Revista Brasileira de Ciências Sociais. São Paulo, v.14, n.41, p.45-67, 1999.

MARTELETO, R.M.; RIBEIRO, B.; GUIMARÃES, C. Informação em movimento: produção e organização do conhecimento nos espaços sociais. Civitas. Porto Alegre, v.2, n.1, p.69-80, 2002.

ORGANIZAÇÃO MUNDIAL DA SAÚDE. Conferência Mundial sobre os Determinantes Sociais da Saúde. Diminuindo as diferenças: a prática das políticas sobre os determinantes sociais de saúde. Documento para discussão. Rio de Janeiro, out 2011. Disponível em: <http://www.who.int/sdhconference/discussion_paper/Discussion_Paper_PT.pdf >. Acesso em: 16 nov 2012.

SCHERER-WARREN, I. Redes de movimentos sociais. 2a ed. São Paulo: Loyola, 1996.

Redes de movimentos sociais na América Latina. Caderno CRH, v.21, n.54, p.505517, set-dez 2008.

STOZ, E.N. Redes sociais e saúde. In: MARTELETO, R.M. (Org). Informação, saúde e redes sociais: diálogos de conhecimentos nas comunidades da Maré. Rio de Janeiro: Fiocruz, 2009, p. 27-42.

WESTPHAL, M.F. et al. Capela em ação e a gestão integrada e participativa de políticas públicas. Relatório Técnico. São Paulo: Fapesp, 2008. 205p.

WHITAKER, F. Rede: uma estrutura alternativa de organização. Revista Mutaçôes sociais. Rio de Janeiro, n.3, s/p, 2002.

\section{Nota}

${ }^{1} \mathrm{O}$ município de São Paulo ocupa uma área de 1.509 km² e tem uma população estimada, em 2006, segundo a Secretaria Municipal de Planejamento (SEMPLA), de 11.091 .442 habitantes. O município está dividido em 96 distritos administrativos agrupados em 31 subprefeituras, criadas em 2002, com o objetivo de melhorar a qualidade dos serviços e democratizar e fortalecer as formas participativas de gestão. A Subprefeitura da Capela do Socorro ocupa uma área de $135 \mathrm{~km}^{2}$ e inclui os distritos administrativos de Socorro, Cidade Dutra e Grajaú. É a subprefeitura de maior contingente populacional no município de São Paulo. Em 2006, a população estimada era de 661.721 habitantes, correspondendo a 5,6 \% da população municipal, segundo a Fundação SEADE. 
${ }^{2}$ A agenda por Cidades Saudáveis faz parte de um conjunto de políticas urbanas implantadas, difundidas e implementadas Organização Mundial da Saúde (OMS) desde os anos 80. Ela se sustenta sobre valores de democracia, equidade, solidariedade, autonomia, justiça social e respeito à diversidade. Reitera-se a visão da complexidade dos problemas dos territórios, as dimensōes da participação de diferentes atores em torno de uma gestão participativa; da intersetorialidade entendida como uma convergência de esforços de diferentes setores da sociedade para produzir políticas integradas que ofereçam respostas às necessidades sociais geradas e das redes sociais que se traduzem na conexão de muitos em interação produtiva.

${ }^{3}$ R. Mendes e C.M. Bógus trabalharam na concepção, pesquisa bibliográfica e redação do texto. J.C.A. Fernandez trabalhou na redação e revisão crítica do texto. M.F. Westphal, coordenadora do projeto que deu origem ao artigo, orientou a elaboração e a redação final do texto.

${ }^{4} \mathrm{O}$ projeto de pesquisa (Protocolo de pesquisa ${ }^{\circ} 2.185$ ) que originou os dados apresentados neste artigo foi apreciado e aprovado pelo Comitê de Ética da Faculdade de Saúde Pública da Universidade de São Paulo (Of. COEP/371/10), de acordo com a Resolução n. 196/96 do Conselho Nacional de Saúde. 
Health promotion and leadership networks The study of social networks has been gaining importance in health promotion because of the horizontality and synergy created by aggregating groups seeking improved living conditions. Some results of the investigation "Capela in Action and the integrated and participative management of public policies", which assessed an administrative model of the Capela do Socorro subprefecture, in southern São Paulo city, are presented. The analysis of the data addressed the relationships between local leaders, their integration into networks and how far these relationships facilitate actions seeking improved living conditions. The universe of leaders and entities was not defined a priori, but empirically from references collected in the field by the snowball technique. Semi-structured interviews identified groups, movements and entities and their relationships with local government. The data identified 247 leadership positions, 342 associations and complexities of the administrative model studied, within the perspective of the construction of social and political networks as instruments of popular participation. Analyses showed that in inter-group relationships, presented as a sociogram, diffuse connections characterized an extensive, sparse network. Changes are underway in civil society, both in organization and social transformation. Some facts pointed here provide local administration with information to create new opportunities for participation and facilitate local leaders' involvement in the implementation of public policies.

> Key words: health promotion; social networks; intersectorial action; social participation. 